\title{
Birth Preparedness and Complication Readiness Practice and Associated factors among Women Attending Antenatal care Follow up in Yirgalem General Hospital, Sidama Zone, Southern Ethiopia, 2019
}

Molalegn Mesele Gesese ( $\nabla$ emimolalegn@gmail.com )

Wolaita Sodo University https://orcid.org/0000-0002-2897-7193

Walellign Anmut Tirfe

Wolaita Sodo University

Research

Keywords: Birth preparedness, complication readiness, Ethiopia, practice

Posted Date: August 19th, 2020

DOI: https://doi.org/10.21203/rs.3.rs-55574/v1

License: (c) (1) This work is licensed under a Creative Commons Attribution 4.0 International License.

Read Full License 


\section{Abstract}

Background: Birth preparedness and complication readiness is an approach that inspires pregnant women, their families and individuals to successfully design strategy for childbirths and deal with emergencies. In developing countries, world health organization estimates that more than $\mathbf{3 0 0}$ million women suffer from short-term and long-term complications related to pregnancy and child birth. In Ethiopia only $32 \%$ women have birth preparedness. The aim of this study is to assess practice and Associated factors of birth preparedness and complication readiness among Women Yirgalem General Hospital, Sidama Zone, Southern Ethiopia, 2019

Methods: Facility based cross-sectional study was conducted from September $1^{\text {st }}$ to $30^{\text {th }}, 2019$. A total of 422 pregnant women were randomly selected and interviewed by using pretested structured questionnaire. Data was entered by Epi-data version 3.1 and the analysis was done by SPSS version 21. Bivariate and multivariable logistic regression was performed to identify factors associated with birth preparedness and complication readiness.

Result: From 422 study participants, 356(48.6\%) (95\% Cl: 46.9\%, 49.8\%) have birth preparedness and complication readiness practice. Age of respondent $\geq 37$ years ( $A O R=4.2,95 \% \mathrm{C} . \mathrm{I}=1.23,14.24)$ and between 25 to 30 (AOR=2.35, 95\% C.I =1.1, 5.1); level of education College and above(AOR=5.59, 95\% C.I $2.8,11.2$ ) and secondary school (AOR=9.5, 95\% C.I 3.99-22); previous history of ANC follow up (AOR=4.33, $95 \%$ C.I $=2.46,7.61)$ and history of birth at health facility (AOR=3.09, 95\% C.I $=1.72,5.56)$ where factors associated with birth preparedness and complication readiness practice.

Conclusion: Relatively higher birth preparedness and complication readiness practice was observed in this study when compared with previous studies. Health extension workers and health care provider should encouraged women to actively utilize the health services and the governments with other stakeholders should works on antenatal care and institutional delivery by focusing on women those has no formal education.

\section{Background}

Globally, more than $40 \%$ of pregnant women may develop acute obstetrics complications. In developing countries, world health organization estimates that more than 300 million women suffer from short-term and long-term complications related to pregnancy and child birth(1). Even if global annual maternal death decrease 303,000 in 2015; from this $99 \%$ from developing country(2). Birth preparedness and complication readiness is an approach that inspires pregnant women, their families and individuals to successfully strategy for childbirths and deal with emergencies, if they occur. It is a key element of worldwide accepted safe motherhood programs(3).

Child birth is unpredictable risk generating conditions, providing timely and sufficient health care for pregnant mothers who face obstetric complication is a possibility for justifying the risk. Identifying and reducing delays in seeking, reaching and obtaining care are the key strategies for timely use of skilled 
maternal and neonatal care, especially during the time of pregnancy, labor and child birth. This can be achieved by one of the essential components of a globally accepted safe motherhood program; birth preparedness and complications readiness is maternal health care services during pregnancy and for potential complications $(4,5)$.

Birth preparedness and complication readiness is amongst the main involvement with the objective to reduce neonatal and maternal mortality through promoting health care seeking behavior and utilization of appropriate skilled personal for delivery and health care facilities(6). The maternal and neonatal health program of Johns Hopkins Program for International Education in Gynecology and Obstetrics (JHIEGO) developed the birth preparedness and complication readiness matrix to address these three delays; (A) is the delay in deciding to seek care for an obstetric complication; (B) Delay to go to health facility after the decision has been made to seek care; and (C) Is the delay in obtaining care once present at the facility(7).From study done in Ethiopia; age, Antenatal Care (ANC) follow up, place of residence, educational status, birth at health facility, history of still birth and knowledge of birth preparedness and complication readiness plan are factors associated with birth preparedness and complication readiness practice $(8,9)$.

Birth preparedness and complication readiness encourages active planning and decision making birth between women and their families and encourages to choice a skill birth attendant; arranging and identifying the appropriate health care facility; preparing transportation to health care facilities for birth and obstetrics emergencies; save money for emergency and birth expenses; identifying an individual to take care for the rest of family when the expectant mother absence; preparing any needed supplies for mother during birth and postnatal period, being aware of the expected date of birth and obstetrics danger signs(10).

\section{Method And Material}

\section{Study setting and design}

Health facility based cross sectional study was conducted in Yirgalem general hospital from September $1^{\text {st }}$ to $30^{\text {th }}, 2019$. Yirgalem general hospital is located in Sidama zone, Southern Nation Nationality People Republic (SNNPR), Ethiopia. Figures from the central statistics agency of Ethiopia published in 2005 indicated that, Yirgalem has an estimated total population of 43,815 of whom 21,975 women and 21,840 are men. Yirgalem town is located at the distance of $260 \mathrm{Km}$ from Addis Abeba the capital city of Ethiopia and $40 \mathrm{Km}$ from Hawassa the capital city of SNNPR. The study was carried out among pregnant women attending Ante Natal Care(ANC) in Yirgalem general hospital from September $1^{\text {st }}$ to $30^{\text {th }}, 2019(11)$.

\section{Source and study population}


All pregnant women who came to Yirgalem general hospital for ANC visit was source population and all pregnant women who fulfill the inclusion criteria and selected pregnant women was study population.

\section{Eligibility criteria}

Pregnant women who can hear and communicate and who are volunteer to participate are included and a Pregnant women with mental problem or seriously ill/ unable to hear and speak was excluded.

\section{Sample size determination and sampling procedure}

The sample size was estimated by using sample size determination for a single population proportion formula. Therefore, the total sample size was calculated with the marginal error of 0.05 , with $95 \%$ confidence interval and p-value 48.5\% from study conducted in Sodo town, Wolaita Zone, SNNPR, Ethiopia(12). A possibility of $10 \%$ of the total sample size was considered for non-respondents. And the final sample size was 422 .

\section{Data collection procedure and instrument}

Data was collected by face to face interview method with structured questionnaire and subjects were selected by systematic random sampling technique. The questionnaire was first developed in English and translated into Amharic; which include; socioeconomic and demographic characteristics, obstetric, health services related factors, means of information, and availability of transport. The questionnaire was taken from maternal and child health program of Johns Hopkins Program for International Education in Gynecology and Obstetrics. The outcome of this study this study is practice of birth preparedness and complication readiness(7).

\section{Operational definition}

Birth preparedness and complication readiness: A women was considered as prepared for birth and its complication if she save money for birth-related and emergency expense; identified place of delivery; skill birth attendants; arrange transport to health institution for delivery and obstetric urgent situation, and prearranged blood donor in cases of obstetrics emergency. The 5 variable were transformed on SPSS in to one variable that is "Birth preparedness and complication readiness practice" women who found at least 3 of the 5 Birth preparedness and complication readiness component were considered as" prepared for birth and its complication" coded as 1 . The remain women who found less than three were considered as "not prepared for birth and its complication" and coded as 0 . This scoring has been previously used in studies that assessed women's Birth preparedness and complication readiness practice(12-14).

\section{Data processing and Analysis}

Data was checked for completeness and entered in to Epi data version 3.1 and SPSS window version 21 was used for analysis. Descriptive analysis was done and results were presented in the form of narrative and table. Bivariate and multivariable logistic regression was done to identify factors associated with 
birth preparedness and complication readiness. All variables with p-value less than 0.25 in bivariate logistic regression model were entered to multivariable logistic regression model for controlling possible confounding and variable with p-value less than or equals to 0.05 in multiple logistic regression model were considered as statistically significant.

\section{Result}

\section{Socio demographics characteristics}

Data were collected from 422 pregnant women who come for ANC follow up in Yirgalem general hospital during study paired with response rets of $99 \%$. The mean age with \pm standard deviation (SD) of respondent age was $26.3 \pm 6.2$ years. Among the respondents $65(15.4 \%)$ of respondents were aged $18-24$ years old and $254(59.7 \%)$ and $138(32.7 \%)$ were no formal education. Majority of the respondents 398(94.3\%) were married (table 1).

Table 1: socio-demographic characteristics of women attending ANC follow up in Yirgalem general Hospital, Sidama Zone, Ethiopia; $2019(n=422)$ 


\begin{tabular}{|c|c|c|}
\hline \multirow[t]{3}{*}{ Variable } & \multicolumn{2}{|c|}{ Birth preparedness and complication readiness } \\
\hline & No & Yes \\
\hline & Frequency (\%) & Frequency (\%) \\
\hline \multicolumn{3}{|l|}{ Age of respondents } \\
\hline $18-24$ & $38(58.5)$ & $27(41.5)$ \\
\hline $25-30$ & $128(50.8)$ & $124(49.2)$ \\
\hline $31-36$ & $43(57.3)$ & $32(42.7)$ \\
\hline $37-44$ & $8(26.7)$ & 22(73.3) \\
\hline \multicolumn{3}{|l|}{ Level of education } \\
\hline No formal education & $100(72.5)$ & $38(27.5)$ \\
\hline Primary education & $65(54.2)$ & $55(45.8)$ \\
\hline Secondary education & $12(24)$ & $38(76)$ \\
\hline College and university & $40(35.1)$ & $74(64.9)$ \\
\hline \multicolumn{3}{|l|}{ Occupation } \\
\hline House wife & $128(60.4)$ & $84(39.6)$ \\
\hline Farmer & 23(29.9) & $54(70.1)$ \\
\hline Merchant & $43(55.1)$ & $35(44.9)$ \\
\hline Government employee & $3(25)$ & $9(75)$ \\
\hline Private employee & $20(46.5)$ & $23(53.5)$ \\
\hline \multicolumn{3}{|c|}{ Estimated monthly imcome (ETB) } \\
\hline$>500$ & $151(55.3)$ & $122(44.3)$ \\
\hline $500-3500$ & $45(43.3)$ & $59(56.7)$ \\
\hline $3600-7000$ & $21(46.7)$ & $24(53.3)$ \\
\hline \multicolumn{3}{|l|}{ Current marital status } \\
\hline Married & $202(50.8)$ & $196(49.2)$ \\
\hline Not married & $10(52.6)$ & $9(47.2)$ \\
\hline separated & $5(100)$ & $0(0)$ \\
\hline \multicolumn{3}{|l|}{ Age at first marriage } \\
\hline None & $8(50)$ & $8(50)$ \\
\hline 14-18 & $131(52)$ & $121(48)$ \\
\hline
\end{tabular}




\begin{tabular}{|c|c|c|}
\hline $19-25$ & $67(55.8)$ & $53(44.2)$ \\
\hline $26-32$ & $6(25)$ & $18(75)$ \\
\hline $33-40$ & $5(50)$ & $5(50)$ \\
\hline \multicolumn{3}{|l|}{ Educational level of husband } \\
\hline No formal education & $116(68.2)$ & $54(31.8)$ \\
\hline Primary education & 25(33.8) & $49(66.2)$ \\
\hline Secondary education & $34(40)$ & $51(60)$ \\
\hline College and university & $42(45.2)$ & $51(54.8)$ \\
\hline \multicolumn{3}{|l|}{ Occupation of husband } \\
\hline No work & $16(76.2)$ & $5(23.8)$ \\
\hline Farmer & $65(45.1)$ & $79(54.9)$ \\
\hline Merchant & $60(55.6)$ & $48(44.4)$ \\
\hline Government employee & 11(31.4) & $24(68.6)$ \\
\hline Daily laborer & $45(64.3)$ & $25(35.7)$ \\
\hline Other & $20(45.5)$ & $24(54.5)$ \\
\hline \multicolumn{3}{|l|}{ Estimated monthly } \\
\hline income of husband (ETB) & $34(45.3)$ & $41(54.7)$ \\
\hline$>500$ & $59(45.4)$ & $71(54.6)$ \\
\hline $500-3500$ & $87(65.4)$ & $46(34.6)$ \\
\hline $3600-7000$ & $37(44)$ & $47(56)$ \\
\hline \multicolumn{3}{|l|}{8000 and above } \\
\hline \multicolumn{3}{|c|}{ Numbers of person live in the house hold } \\
\hline \multicolumn{3}{|l|}{ None } \\
\hline $1-4$ & $88(56)$ & $69(44)$ \\
\hline \multirow[t]{2}{*}{ 5-8 } & 118(48) & $128(52)$ \\
\hline & $11(57.9)$ & $8(42.1)$ \\
\hline \multicolumn{3}{|c|}{ Decision maker in the house hold } \\
\hline Herself & $18(54.5)$ & $15(45.5)$ \\
\hline Husband & $48(55.8)$ & \\
\hline Self and husband & $142(48.3)$ & $39(44.2)$ \\
\hline
\end{tabular}




\section{Obstetrics characteristics of participants}

Regarding obstetrics characteristics of participantstwo hundred five (48.6\%) have attend ANC during last pregnancy. in related outcome face during pregnancy, 74 have face abortion, one hundred seventy eight live birth, only five still birth. 177(42\%) start antenatal care during 16 week of gestation (table 2).

Table 2: Obstetrics characteristics of women attending ANC follow up in Yirgalem general Hospital, Sidama Zone, Ethiopia; $2019(n=422)$ 


\begin{tabular}{|c|c|c|}
\hline \multirow[t]{3}{*}{ Variable } & \multicolumn{2}{|c|}{ Birth preparedness and complication readiness } \\
\hline & No & Yes \\
\hline & Frequency (\%) & Frequency (\%) \\
\hline \multicolumn{3}{|l|}{ Parity } \\
\hline Nulliparous(0) & $68(46.3)$ & 79(53.7) \\
\hline Primiparous \& multiparous(1-4) & $96(50)$ & $96(50)$ \\
\hline Grand multiparous $(\geq 5)$ & $53(63.9)$ & $30(36.1)$ \\
\hline \multicolumn{3}{|l|}{ Age at first pregnancy } \\
\hline$<18$ & $45(55.6)$ & $36(44.4)$ \\
\hline $18-25$ & $62(48.1)$ & $67(51.9)$ \\
\hline $26-36$ & $93(55)$ & $76(45)$ \\
\hline $36-45$ & 17(39.53) & $26(60.47)$ \\
\hline \multicolumn{3}{|l|}{ Outcome face during pregnancy } \\
\hline \multicolumn{3}{|l|}{ None } \\
\hline Abortion & $53(61.6)$ & $33(38.4)$ \\
\hline Live birth & $35(47.3)$ & $39(52.7)$ \\
\hline Still birth & $82(46.1)$ & $94(53.9)$ \\
\hline \multirow[t]{2}{*}{ Other } & $0(0)$ & $5(100)$ \\
\hline & $47(59.5)$ & $32(40.5)$ \\
\hline \multicolumn{3}{|l|}{ Presence of pregnancy now } \\
\hline Yes & $212(51.5)$ & $200(48.5)$ \\
\hline No & $5(50)$ & $5(50)$ \\
\hline \multicolumn{3}{|l|}{ Previous ANC follow up } \\
\hline Yes & $150(48.1)$ & $162(51.9)$ \\
\hline No & $67(60.9)$ & 43(39.9) \\
\hline \multicolumn{3}{|l|}{ ANC is useful } \\
\hline Yes & $163(46.7)$ & $186(53.3)$ \\
\hline No & $54(74)$ & $19(26)$ \\
\hline \multicolumn{3}{|l|}{ Birth at health facility } \\
\hline Yes & $110(41.8)$ & $153(58.2)$ \\
\hline
\end{tabular}




\begin{tabular}{|lll|} 
No & $106(67.1$ & $52(32.9)$ \\
Beek to start ANC 16 week & & \\
$16-28$ week & $40(37.4)$ & $67(62.6)$ \\
$28-34$ week & $97(54.8)$ & $80(45.2)$ \\
$34-40$ week & $67(60.4)$ & $44(39.6)$ \\
\hline Time of attending ANC in last pregnancy & $13(48.1)$ & $14(51.9)$ \\
None & & \\
One & $49(47.1)$ & $55(52.9)$ \\
Twice & $20(69)$ & $9(31)$ \\
Three time & $26(61.9)$ & $16(38.1)$ \\
Four and above & $26(38.2)$ & $42(61.8)$ \\
& $96(53.6)$ & $83(46.4)$ \\
\hline
\end{tabular}

\section{Women's birth preparedness plan and complication readiness}

The Birth Preparedness and Complication Readiness (BPCR) score was computed from key 5 elements of BPCR. By considering three or more steps of this 5 components, 356(48.6\%) (95\% Cl: $46.9 \%, 49.8 \%)$ were found to fulfill the criteria and measured as ready for birth and its complication (table 3 ).

Table 3: Women's birth preparedness plan and complication readiness among women attending ANC follow up in Yirgalem general Hospital, Sidama Zone, Ethiopia; 2019 ( $n=422)$ 


\begin{tabular}{|c|c|c|}
\hline Variable & Frequency & Present (\%) \\
\hline \multicolumn{3}{|l|}{ Plan for place of delivery } \\
\hline Yes & 356 & 84.4 \\
\hline No & 66 & 15.6 \\
\hline \multicolumn{3}{|l|}{ Plane for which place of delivery } \\
\hline Home & 61 & 14.45 \\
\hline Health center & 135 & 32 \\
\hline Hospital & 154 & 36.5 \\
\hline \multicolumn{3}{|l|}{ Couse to prefer to deliver at health facility } \\
\hline None & 125 & 29.6 \\
\hline Health facility is near to me & 22 & 5.2 \\
\hline Give better service & 222 & 52.6 \\
\hline I had better out come before & 15 & 3.6 \\
\hline Health workers activity & 22 & 5.2 \\
\hline I have problem with previous home delivery & 16 & 3.8 \\
\hline \multicolumn{3}{|l|}{ Preparation done } \\
\hline Grain for porridge & 96 & 22.7 \\
\hline Cloth for new born & 61 & 14.5 \\
\hline Identified helper & 44 & 10.4 \\
\hline \multirow[t]{2}{*}{ No preparation } & 221 & \\
\hline & & 52.36 \\
\hline \multicolumn{3}{|l|}{ Save money for previous delivery } \\
\hline Yes & 233 & 55.2 \\
\hline No & 189 & 44.8 \\
\hline \multicolumn{3}{|l|}{ Plane for transport for emergency } \\
\hline Yes & 248 & 58.8 \\
\hline No & 174 & 41.2 \\
\hline \multicolumn{3}{|l|}{ Prepare blood donor } \\
\hline Yes & 105 & 24.9 \\
\hline No & 317 & 75.1 \\
\hline
\end{tabular}




\section{Persons going with you}

Husband

Relatives

Community emergency committee

Health care provider

None
76

57

10

4

275
18

13.5

2.4

0.9

65.2

\section{Factors influencing practice of birth preparedness and complication readiness}

In Multivariable regression analysis age of respondents, level of education, outcome face during pregnancy and child birth , antenatal care follow up is useful, attend antenatal care during last pregnancy and birth at health facility where significantly associated with practice of birth preparedness and complication readiness.

Birth preparedness and complication readiness practice is higher among older age group than younger age group; age group 37-44 where four time more practicing birth preparedness and complication readiness $(A O R=4.2,95 \%$ C.I $=1.23,14.24)$ and age group from 25 to 30 where more than two fold birth preparedness and complication readiness practice (AOR=2.35, 95\% C.I =1.1, 5.1)than those with age group 18-24 years. Educational level was another significantly associated with birth preparedness and complication readiness practice. From the respondents those whose educational level is college, University and above are more than 5 time have birth preparedness and complication readiness practice ( $A O R=5.59,95 \%$ C.I 2.8, 11.2) than educational level with no formal education, with secondary school more than 9 time (AOR=9.5, 95\% C.I 3.99-22) more likely to have birth preparedness practice than no formal education and primary school education more than 2.8 time (AOR=2.8, 95\% C.I 1.46-5.38) more likely to have birth preparedness practice than no formal education.

Another significantly associated factor with birth preparedness and complication readiness was history of antenatal care follow up; those who have previous history of antenatal care follow up have 4.33 time more likely to have birth preparedness and complication readiness practice (AOR=4.33,95\% C.I $=2.46$, 7.61) than those who have no history of antenatal care follow up and from respondents who say "antenatal care follow up is useful" have 3.99 time birth preparedness and complication readiness practice $(A O R=3.99,95 \%$ C.I $=2.06,7.72)$ than those who have say antenatal care is not useful. Birth at health facility was another factor have significantly associated with birth preparedness and complication readiness practice. Those who have a history of birth at health facility have more likely to have birth preparedness and complication readiness practice (AOR=3.09, 95\% C.I $1.72,5.56$ ) than those who have no history of birth at health facility (table 4). 
Table 4: factors affecting birth preparedness and complication readiness practice adjusted for confounding variable in Yirgalem general Hospital, Sidama Zone, Ethiopia; 2019 ( $n=422)$ 
Variable

birth preparedness and complication

readiness practice
Crude OR

(95\% C.I)
Adjusted OR

(95\% C.I)

\section{Age of respondents}

\begin{tabular}{|c|c|c|c|c|}
\hline $18-24$ & $38(58.5)$ & $27(41.5)$ & 1 & 1 \\
\hline $25-30$ & $128(50.8)$ & $124(49.2)$ & $1.36(0.78,2.36)$ & $2.35(1.07,5.15)^{*}$ \\
\hline $31-36$ & $43(57.3)$ & $32(42.7)$ & $1.04(0.53,2.05)$ & $0.87(0.32,2.33)$ \\
\hline $37-44$ & $8(26.7)$ & $22(73.3)$ & $3.87(1.50,9.98)$ & $4.17\left(1.22(14.24)^{*}\right.$ \\
\hline \multicolumn{5}{|l|}{$\begin{array}{l}\text { Respondents level } \\
\text { of education }\end{array}$} \\
\hline No formal education & 100(72.5) & $38(27.5)$ & 1 & 1 \\
\hline Primarv educatio & $65(54.2)$ & $55(45.8)$ & $2.22(1.32,3.73)$ & $2.80(1.46,5.38)^{\star}$ \\
\hline Conaly evacationi & $12(24)$ & $38(76)$ & $8.33(3.94,17.62)$ & $9.52(3.99,22.68)^{*}$ \\
\hline $\begin{array}{l}\text { Secondary } \\
\text { education }\end{array}$ & $40(35.1)$ & $74(64.9)$ & $4.862 .84,8.32)$ & $5.59(2.79,11.20)$ \\
\hline
\end{tabular}

\section{Outcome face}

during pregnancy

None

53(61.6)

33(38.4)

1

1

35(47.3)

39(52.7)

$0.91(0.49,1.9)$

$1.33(0.55,3.20)$

Abortion

82(46.1)

94(53.9)

$1.83(0.86,3.1)$

$3.53(1.51,8.25)$

$0(0)$

$5(100)$

$1.72(1.01,2.94)$

$1.55(0.73,3.28)$

Still birth

Other

47(59.5)

32(40.5)

$2.23(1.36,7.32)$

\section{Age at first \\ pregnancy}

$<18$

18-25

26-36

36-45

$$
\text { 45(55.6) }
$$

62(48.1)

93(55)

17(39.53)
36(44.4)

67(51.9)

76(45)

26(60.47)
$2.16(1.7,6.67)$

1.63(0.53,4.98)

$6.00(1.52,23.6)$

1
$1.76(0.44,7.00)$

$1.01(0.26,3.80)$

$5.67(1.14,28)$

\section{Previous ANC follow}

up

Yes

No

$\begin{array}{llll}150(48.1) & 162(51.9) & 3.86(1.08,2.62) & 4.33(2.46,7.61)^{*} \\ 67(60.9) & 43(39.9) & 1 & 1\end{array}$




\begin{tabular}{|lllll|} 
Yes & $163(46.7)$ & $186(53.3)$ & $1.84(1.84,5.69)$ & $3.99(2.06,7.72)^{\star}$ \\
No & $54(74)$ & $19(26)$ & 1 & \\
\hline $\begin{array}{l}\text { Birth at health } \\
\text { facility }\end{array}$ & & & & \\
Yes & $110(41.8)$ & $153(58.2)$ & $2.83(1.87,4.28)$ & $3.09(1.7,5.56)^{*}$ \\
No & $106(67.1$ & $52(32.9)$ & 1 & \\
\hline
\end{tabular}

\section{*Significant association at P-value $<0.05$}

\section{Discussion}

This study reveals that the practice of birth preparedness and complication readiness was (48.6\%) (95\% Cl: $46.9 \%, 49.8 \%)$. Reported in the present study is in line with the study done in Wolaita Sodo town southern Ethiopia (8) and in rural community in southern Nigeria $48.4 \%(15)$. The similarity may be due to similarity in methodology and socio-demographic characteristics.

The finding observed in this study higher with as compared with a study done in Jimma Zone, south west Ethiopia(23.3\%)(16), Dale District, southern Ethiopia (22.5\%)(17), Adigrat town, North Ethiopia $(22 \%)(18)$, and the study done in Goba, East Ethiopia (29.9\%)(19). The difference might be due to the time, the current study conducted after a lot of work done by multi-sectoral collaboration to enhance mother birth preparedness and complication readiness through one -to- five networks health extension workers.

Birth preparedness and complication readiness practice is higher among older age group than younger age group; age group $\geq 37$ where four time ( $A O R=4.2,95 \%$ C.I $=1.23,14.24)$ and age group from 25 to 30 where more than two fold $(A O R=2.35,95 \% C . I=1.1,5.1)$ more likely practicing birth preparedness and complication readiness than age group 18-24. The finding is in line with the study conducted in India among women beneficiaries of selected rural primary health center of Dakshina district, Karnataka(20). The possible reason is that younger women may have no previous obstetrics complication that makes them to prepare themselves but the old women they have a history of obstetrics complication they prepare themselves for their current pregnancy (not assessed in study). This study finding differ from study conducted in Wolaita Zone, Sodo town, that indicated younger age groups are more likely to birth preparedness and complication readiness practice(12). The observed difference might be because of older women in Sodo town may be traditional and they might accept as they feel safe as they deliver at home and the older women are less likely to birth preparedness and complication readiness.

Educational level was another significantly associated with birth preparedness and complication readiness practice. From the respondents those whose educational level college, University and above are more than 5 time (AOR=5.59, 95\% C.I 2.8, 11.2), educational level with secondary school more than 9 time $(A O R=9.5,95 \%$ C.I 3.99-22) and primary school education more than 2.8 time (AOR=2.8, 95\% C.I 1.46- 
5.38) more likely to have birth preparedness and complication readiness practice than no formal education. The finding of this study was in line with the study done in Wolaita zone, Sodo town, Southern Ethiopia and Robe Woreda, Arisi zone, Central Ethiopia $(12,21)$. The reason might be Education give a greater health care seeking behaviors of women and education build self-confidence and decision making ability that enhance their birth preparedness and complication readiness.

History of ANC has a positive association with birth preparedness and complication readiness practice; those who have previous history of antenatal care follow up have 4.33 time more likely to had birth preparedness and complication readiness practice (AOR=4.33, 95\% C.I $=2.46,7.61)$ than those who have no history of antenatal care follow up. This study is in line with a study done in Adigrat town, Ethiopia and Wolaita Zone, Sodo town, southern Ethiopia(12, 22). The reason might be during ANC the health provider gives health education in birth preparedness and complication readiness and their previous exposure will increase women's knowledge and practice. Women who say "ANC is useful" have 3.99 time more likely to have birth preparedness and complication readiness practice (AOR=3.99, 95\% C.I $=2.06$, 7.72) than those who have say antenatal care is not useful. This is due to if they agree as ANC is useful, they have birth preparedness and complication readiness.

Birth at health facility was another factor have significantly associated with birth preparedness and complication readiness practice. Those who have a history of birth at health facility have more likely to have birth preparedness and complication readiness practice (AOR=3.09, 95\% C.I $=1.72,5.56)$ than those who have no history of birth at health facility. The finding of this study is similar with study done in Dale District, Southern Ethiopia(23). The reason might be their contact to health institution help the women to get health education for birth preparedness and complication readiness practice.

This study has a few limitations. First it is institution based study that addresses only women who come to health institution those women who doesn't come to health institution missed to assess their birth preparedness and complication readiness practice. The cross sectional nature of this study may not elucidatetemporal relationship between the dependent and independent variable.

\section{Conclusion}

Relatively higher birth preparedness and complication readiness practice was observed in this study when compared with previous study. age of respondents, level of education, age at first pregnancy, outcome face during pregnancy and child birth, previous antenatal care follow up and birth at health facility were found to be significantly associated with birth preparedness and complication readiness practice.

The government has to work in collaboration with different stockholder universal coverage of education and health education by strengthen the communication system with community to increase BPCR practice and focus on younger women and increase ANC follow up and institutional delivery coverage from health care provider also expected to do not miss the opportunity to disseminate all information related BPCR practice. 


\section{Abbreviations}

AOR: Adjusted Odd Ratio; ANC: Ante Natal Care; BPCR: Birth Preparedness Complication Readiness; ETB: Ethiopian birr; JHIEGO: Johns Hopkins Program for Institutional Education in Gynecology and Obstetrics; SNNPR: Southern Nation Nationality People Republic

\section{Declarations}

\section{Acknowledgment}

We would like to express our heartfelt thanks to Yirgalem general hospital administers and all staff member who work in Antenatal care service and all respondents for their cooperation during our data collection

\section{Funding}

Research and Academic Review Board of Wolaita Sodo University, college of health science was involved in monitoring and evaluation of the work. But this organization did not involve in designing, analysis and critical review of this intellectual content, preparation for publication and the budget funded by this organization did not include for publication.

\section{Availability of data and materials}

All data and materials are available in the manuscript

\section{Authors' contributions}

MM wrote the proposal, participates in data collection, data analysis and wrote the manuscript WA made some revision on proposal; participate in data analysis and manuscript preparation.

\section{Ethics approval and consent to participate}

Ethical approval was obtained from Wolaita Sodo University College of health science and medicine Ethical review board. Permission was obtained from Yirgalen town health office and Yirgalem Hospital.The purpose and objective of the study was well explained to study participants and they were informed about their full right to withdrawal or discontinue participation at any time they want. In addition privacy and confidentiality of participant was kept.

\section{Consent for publication}

It is not applicable

\section{Computing interest}

The authors declare that they have no competing interests 


\section{References}

1. WHO. World Health Organization Department of Making Pregnancy Safer. WHO, Geneva, Switzerland.. 2009.

2. Alkema L, Chou D, Hogan D, Zhang S, Moller AB, Gemmill A, et al. Global, regional, and national levels and trends in maternal mortality between 1990 and 2015, with scenario-based projections to 2030: a systematic analysis by the UN Maternal Mortality Estimation Inter-Agency Group. Lancet. 2016;387:462-74.

3. Acharya AS, Kaur R, Prasuna JG, N R. Making pregnancy safer Birth preparedness and complication readiness study among antenatal women attendees of a primary health center. . India Journal of Community Medicine. 2015;40(2):127-34.

4. Kebebush Z, K. M. Birth preparedness and complication readiness among rural women of reproductive age in abeshige district, guraghe zone, SNNPR, Ethiopia. Int J Women's Health. 2017;9:11-21.

5. Affipunguh PK, AS L. Assessment of knowledge and practice towardsbirth preparedness and complication readiness among women in northern Ghana: a cross-sectional study. . International Journal of Scientific Reports. 2016;2(6):121-9.

6. Bintabara ea. Birth preparedness and complication readiness among recently delivered women in chamwino district, Central Tanzania: a cross sectional study. Reprod Health. 2015;12(44).

7. (JHPIEGO). JHPfIEiGO. Maternal and Neonatal Health (MNH) Program, birth preparedness and complication readiness. A matrix of shared responsibilities. Maternal and neonatal health. Available at: http://wwwjhpiegoorg/files/bpcrmatrixpdf. 2001.

8. Azeze, al. e. Birth preparedness and complication readiness practice and influencing factors among women in Sodo town, Wolaita zone, Southern Ethiopia, 2018; community based cross-sectional study. BMC Reproductive Health. 2019.

9. Miteku Andualem Limenih, Habitamu Gebrehana Belay, Habitamu Abie Tassew. Birth preparedness, readiness planning and associated factors among mothers in Farta district, Ethiopia: a crosssectional study. BMC Pregnancy and Childbirth. 2019:8-9.

10. Phanice KO, Yaw AA, O. P. Birth preparedness and complication readiness among women attending antenatal Care Clinic in Health Facilitieswithin Bureti Sub County of Kericho County, Kenya. . American Journal of Medicine and Medical Sciences 2016;6(4):123.

11. Central Statistics Agency, Ethiopia. 2005.

12. Azeze, et, al. Birth preparedness and complication readiness practice and influencing factors among women in Sodo town, Wolaita zone, Southern Ethiopia, 2018; community based cross-sectional study. BMC Reproductive health. 2019:12978-019-0703-z.

13. Bintabara, al e. Birth preparedness and complication readiness amongrecently delivered women in chamwino district, Central Tanzania: a crosssectional study. Reprod Health [Internet]. 2015;12(44). 
14. JHPIEGO. Monitoring birth preparedness and complication readiness tools and indicators for maternal and newborn health. . JHPIEGO. 2004.

15. badin $\mathrm{SH}$, et, al. Birth preparedness and complication readiness among pregnant women in a rural community in southern Nigeria South African Journal of Obstetric and Gynecology 2016;22(2):4751.

16. Gurmesa TD, Mesganaw FA, Alemayehu WY. Factors affecting birth preparedness and complication readiness in Jimma zone, Southwest Ethiopia: a multilevel analysis. Pan African Medical Journal. 2014:19(272).

17. Bizuayehu Bogale, Ayalew Astatkie, Wakgari N. Effect of Pregnant Mothers' Forum Participation on Birth Preparedness and Complication Readiness among Pregnant Women in Dale District, Southern Ethiopia: A Comparative Cross-Sectional Study. Hindawi Journal of Pregnancy. 2019.

18. M. Hiluf, Fantahun M. "Birth preparedness and complication readiness among women in Adigrat town, north Ethiopia,". Ethiopian Journal of Health Development5r4ere. 2007;22.

19. Desalegn M, Daniel B. Birth preparedness and complication readiness among women of child bearing age group in Goba woreda, Oromia region, Ethiopia. . BMC Pregnancy and Childbirth. 2014;14(10.1186/1471-2393-14-).

20. KibballiMA, SiddharudhaS. Birth preparedness and complication readiness among the women beneficiaries of selected rural primary health centers of Dakshina Kannada district, Karnataka, India. . PLoS One. 2017;8:12.

21. Muhammedawel K, A. M. Birth preparedness and complication readiness in robe Woreda, Arsi zone, Oromia region, Central Ethiopia: a cross-sectional study. . Reprod Health. 2014:11(55).

22. Mihret $H$, Mesganaw F. Birth preparedness and complication readiness among women in Adigrat town, North Ethiopia. Ethiopian Journal of Health and Development. 2007(22):14-20.

23. et.al BB. Effect of Pregnant Mothers' Forum Participation on Birth Preparedness and Complication Readiness among Pregnant Women in Dale District, Southern Ethiopia: A Comparative CrossSectional Study. Joural of pregnancy Hindawi. 2019. 